\title{
ESTUDIOS ARQUEOMÉTRICOS MULTIPROXI EN CERÁMICA DE LA LOCALIDAD ARQUEOLÓGICA MELIQUINA, NEUQUÉN, ARGENTINA. AVANCES Y RESULTADOS
}

\author{
MULTIPROXIAL ARCHAEOMETRIC STUDIES IN CERAMICS TO \\ MELIQUINA ARCHAEOLOGICAL LOCALITY, NEUQUÉN, ARGENTINA. \\ ADVANCES AND RESULTS
}

\author{
Alberto Enrique Pérez ${ }^{1}$ \\ Recibido 30 mayo 2020. Aceptado 18 agosto 2020
}

\begin{abstract}
Resumen: Se presenta una síntesis de los avances en las investigaciones sobre alfarería de la Localidad Arqueológica Meliquina (LAM), en ambiente boscoso y lacustre del sector meridional de la provincia de Neuquén, Argentina. La estrategia de análisis no se basó en estudios tipológicos que utilizan las capacidades y limitaciones potenciales por aspectos formales, sino en la descripción de resultados de distintos análisis arqueométricos desde un abordaje multiroxi, organizados en estudios de procedencia, estructurales y funcionales. Entre los estudios de procedencia identificamos mediante TXRF arcillas de disponibles inmediata y otro grupo químico no local. Respecto a los estudios estructurales, mediante imágenes radiográficas observamos manufactura por superposición y elevación en espiral de rollos. En cuento a los estudios funcionales, mediante Cromatografía Gaseosa identificamos ácidos grasos de hojas, bayas y semillas entre los residuos adheridos, junto a improntas negativas analizados mediante Microscopia de Barrido Electrónico identificadas con Bromus sp. y otras especies no locales domesticadas como el maíz a partir de fitólitos y almidones. La activación, cultivo e identificación molecular de levaduras fermentativas criotolerantes, junto a fitolitos y almidones termoalterados de granos de maíz sugieren que, al igual que otras semillas y frutos, puedan ser parte del procesamiento o contención de bebidas fermentadas.
\end{abstract}

Palabras claves: Alfarería arqueológica, Patagonia, Arqueometría, análisis multiproxi.

\begin{abstract}
A synthesis of the advances in pottery research of the Meliquina Archaeological Site (LAM) is presented, in a wooded and lacustrine environment in the southern sector of the province of Neuquén, Argentina. The analysis strategy was not based on typological studies that used the potential capacities and limitations for formal aspects, but on the description of results of different archeometric analyzes from a multiroxi approach, organized in provenance, structural and functional studies. Among the provenance studies, we identified immediately available clays and another non-local chemical group by TXRF. Regarding structural studies, we observed manufacturing by superimposition and spiral elevation of rolls using radiographic images. Regarding functional studies, by Gas Chromatography we identified fatty acids from leaves, berries and seeds among the adhered residues, together with negative imprints analyzed by means of Electronic Scanning Microscopy identified with Bromus sp. and other domesticated non-local species such as corn from phytoliths and starches. The activation, cultivation and molecular identification of cryotolerant fermentative yeasts, together with phytoliths and thermo-altered starches from corn kernels suggest that, like other seeds and fruits, they may be part of the processing or containment of fermented beverages.

Keywords: archaeological pottery, Patagonia, Archeometry, multiproxy analysis
\end{abstract}

\section{Introducción}

Hasta el siglo pasado los estudios de la cerámica arqueológica de la Patagonia trasladaron el desarrollo teórico y metodológico de otras áreas como el noroeste Argentino (Di Prado, 2017; Pérez, 2020). Durante las últimas dos décadas el camino hacia una identidad regional o sureña de la disciplina comenzó a configurarse, incorporando modelos desarrollados para abordar la emergencia y los procesos de cambio de la alfarería en sociedades cazadoras recolectoras, proceso que en la década de 1990 tiene su auge en las reuniones de especialistas que comienzan a visibilizar el uso de alfarería entre sociedades móviles y que tiene un sistema económico mayoritariamente apropiador de recursos naturales. Me refiero a "The emergence of pottery. Technology and innovation in ancient societies" editado por Barnett \& Hoopes en 1995 y a "Pottery and People. A Dynamic Interac- tion" editado por Skibo \& Feinman en 1999. Donde más de una docena de artículos serán discutidos y sintetizados por M. Rice en 1999, generando un corpus teórico metodológico que será aplicado para abordar la emergencia de la tecnología cerámica de otras regiones del mundo como el caso de Eurasia (ver Jordan \& Zbelevil en su compilación de 2009). En la misma línea, desde el año 2009 buscamos aplicar distintos modelos en la Patagonia Noroccidental de Argentina (Pérez, 2011) y área centro sur de Chile (Pérez, 2020). El uso de estos modelos estimuló el uso de nuevas metodologías y técnicas, principalmente estudios arqueométricos (Watchman, 2001; Wells, 2018) aplicando diversos análisis que en otras áreas del país cuentan con más años de de-

1 Departamento de Antropología, Facultad de Ciencias Sociales y Humanidades. Universidad Católica de Temuco. Manuel Montt \#56, Temuco, La Araucanía. Chile. aperez@uct.cl 


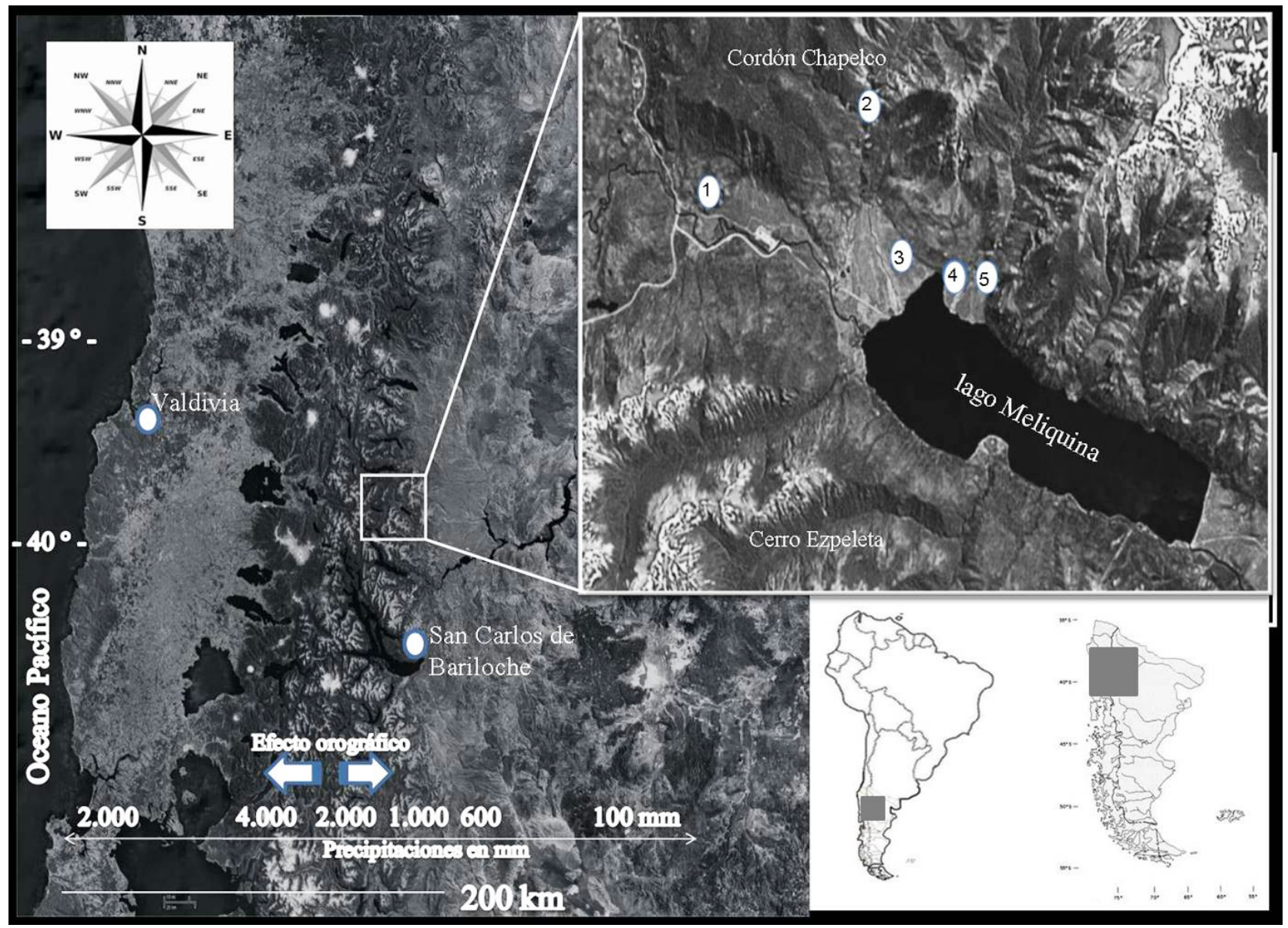

Figura 1. Localidad Arqueológica Meliquina.

1: Cueva Parque Diana, 2: Alero Doña Mica, 3: Valle Meliquina, 4: Lago Meliquina, FS y FM, 5: Las Cachañas.

sarrollo, como por ejemplo, la procedencia de materias primas a través de la petrografía y más recientemente mediante activación neutrónica, los estudios físico químicos para determinar el uso de los artefactos cerámicos por medio de cromatografía gaseosa, isotopos estables, DNA, y los estudios de sustancias adheridas que incluyen materiales antracológicos, sílico-fitolíticos, almidones, polen, diatomeas (Schuster, 2020).

En este trabajo se presenta una síntesis de los estudios realizados sobre los conjuntos cerámicos de la Localidad Arqueológica Meliquina (en adelante LAM), los cuales desde un principio fueron abordados desde un enfoque arqueométrico de carácter multiproxi (Skibo, Malainey \& Kooiman, 2016). Me interesa particularmente discutir la viabilidad de la aplicación de diversas técnicas analíticas, incluso en muestras procedentes de ambientes que se presumen de baja expectativa de supervivencia de materiales orgánicos (humedad, $\mathrm{pH}$ del suelo, incendios forestales, entre otros), como el bosque patagónico (García, 2010).

\section{Estudios cerámicos en la LAM}

Hasta la fecha, se publicaron resultados parciales de los conjuntos cerámicos, cuyos análisis han incluido los aspectos cuali y cuantitativos de cuatro agregados procedentes de contextos estratificados de Cueva Parque Diana (CPD) y superficiales y estratificados de Lago Meliquina Faja Superior, Sector 1 (LM-FS, S1) y Lago Meliquina, Faja Media, Sectores 1 y 2 (LM-FM, S1 y S2) (Figura 1). Un análisis primario permitió establecer características compartidas con los conjuntos conocidos para sitios contemporáneos de la vertiente occidental cordillerana (Pérez, 2010). Los trabajos realizados incluyen estudios experimentales sobre atributos de improntas de hojas por medio de técnicas de reserva (Pérez, Reyes \& Hermann, 2012), fracturas geométricas (Pérez, Sugrañes \& Otaño, 2015) y discusiones sobre atributos modelados denominados protúberos (Pérez, 2011) o anfibiomorfos (Pérez, Schuster \& Jofré, 2018). Sin embargo, y con el objetivo de superar los estudios tipológicos basados en criterios estilísticos y morfológicos/funcionales, hemos abordado a los conjuntos cerámicos de la LAM desde un enfoque arqueométrico multiproxi (ver Skibo et al., 2016), que incluyó: a- estudios de procedencia mediante análisis de composición de las pastas por medio de análisis de Reflexión Total de Fluorescencia por Rayos X, y b- funcionales donde los aspectos morfológicos y decorativos pasaron a un segundo plano. Entre estos últimos distinguimos los análisis de marcas y huellas realizadas sobre la superficie (interna y externa) mediante el cual se pudo identificar por medio de Microscopía de Barrido Electrónico atributos bio y morfométricos específicos derivados de la aplicación intencional de cariópsis. 


\section{El área de estudio}

La Localidad Arqueológica Meliquina (en adelante LAM) se encuentra ubicada en el Departamento Lácar, Provincia de Neuquén, Patagonia Noroccidental Argentina. Las coordenadas aproximadas del punto equidistante entre los sitios que la integran son $40^{\circ} 19^{\prime} \mathrm{S}$ y $71^{\circ} 19^{\prime} \mathrm{W}$. El área de estudio comprende la margen este del lago Meliquina, el valle aluvional que desemboca en el mismo y varios cañadones alimentados por manantiales y por el deshielo del interior del Cordón de Chapelco, que escurre a través de los cañadones Largo y Las Cachañas, y una superficie aproximada de 3.500 hectáreas, donde encuentran varios sitios arqueológicos, y consideramos además un área de $10 \mathrm{~km}$ alrededor del lago homónimo como área potencial de explotación (Figura 1).

La LAM está compuesta por cinco sitios arqueológicos potencialmente articulados funcionalmente, dos bajo reparo rocoso (Cueva Parque Diana y Alero Doña Mica) y tres a cielo abierto (Valle Meliquina, Las Cachañas y Lago Meliquina, FS y FM), con contextos cerámicos datados entre 1.090 y 580 años A.P. Se trata de sitios de interior de bosque (sensu Pérez, 2010), pertenecientes al periodo Alfarero Temprano (Pérez, 2011, 2016), haciendo extensivo la caracterización propuesta por la arqueología chilena al identificar en el sector oriental varios de los atributos compartidos con las denominadas expresiones cordilleranas y tardíos del Complejo Pitrén, o Tradición Arqueológica de los Bosques Templados del Centro Sur de Chile (en adelante TABT) (Adán et al., 2016). Por ejemplo, la presencia de alfarería negro sobre colorado, improntas de hojas por medio de reserva, asas puente, entre otros atributos (Pérez, 2010).

\section{Los conjuntos cerámicos de la LAM}

A continuación presentaré algunos aspectos cuali-cuantitativos de los conjuntos cerámicos de la LAM, para luego centrarme en los diversos análisis que han sido realizados y publicados.

\section{Cueva Parque Diana (CPD)}

Las ocupaciones cerámicas están presentes en dos componentes de ocupación del sitio. El Componente Superior tiene dos fechados: $580 \pm 60$ años AP para la planta 2 (LP-1695, carbón vegetal), y para la planta 3 de $760 \pm 60$ años A.P. (LP-1697, carbón vegetal). El Componente Medio tiene dos fechados radiocarbónicos, uno de $900 \pm 60$ años AP para la planta 6 (LP-1713, carbón vegetal) y otro para la planta 8 de $990 \pm 60$ años A.P. (LP-1720, carbón vegetal). Cabe aclarar que en este trabajo presentamos las cronologías sin calibrar.

La muestra está compuesta por un total de 67 artefactos cerámicos, todos fragmentos (Tabla 1). Entre ellos, 63 (94\%) son tiestos de cuerpo-base, uno (1,5\%) es un fragmento de asa y tres (4,5\%) son bordes. El número mínimo de vasijas estimado es de seis.

\section{Lago Meliquina (LM)}

\section{Lago Meliquina, Faja Media (LM-FM)}

La muestra está dividida en dos sectores: LM-FM, Sector 1, con una muestra de 1.435 artefactos cerámicos recuperados en 10 $\mathrm{m}^{2}$, y LM-FM, datado en $920 \pm 60$ años A.P. (LP-1721, madera carbonizada). En el Sector 2, se recuperaron 327 fragmentos cerámicos de $1 \mathrm{~m}^{2}$ de excavación (Tabla 1). Cabe aclarar que ambos sectores son parte de un mismo agregado o conjunto compuesto por artefactos culturales concentrados en la Faja Media del sitio Lago Meliquina.

Sector 1: Un total de $1.184(83,2 \%)$ artefactos son tiestos parte de cuello-cuerpo sin decoración, 74 (5,2\%) son bordes, seis son bordes decorados, en su mayoría incisos, donde incorporando los bordes decorados suman un total de 119 artefactos decorados incisos (8,36\%). Los fragmentos de asas suman 24 (1,68\%), los tiestos horadados son tres $(0,21 \%)$. También contamos con la presencia de un artefacto circular de borde pulido, con relieve positivo al pastillaje, tipo mamelón o protúbero $(0,07 \%)$ y un fragmento de tubo de pipa $(0,07 \%)$. Finalmente, $17(1,19 \%)$ artefactos han sido asignados la categoría de "Otros" por sus características singulares aunque no diagnósticas.

La muestra de LM-FM, S2 consta de 327 artefactos cerámicos, entre ellos $268(81,95 \%)$ fragmentos sin decoración, parte de cuello-cuerpo; 43 (2,75\%) son fragmentos de cuerpo y cuello decorados, entre los que incluimos 40 con decoración incisa sobre alfarería monocroma y tres con pintura negativa por reserva negro sobre engobe colorado. Fueron identificados además nueve $(2,75 \%)$ bordes, tres $(0,91 \%)$ asas, entre éstas un asa puente, un $(0,30 \%)$ artefacto horadado y tres $(0,90 \%)$ instrumentos indeterminados.

\section{Lago Meliquina, Faja Superior (LM-FS)}

Durante la prospección y los primeros relevamientos de LMFS se recolectaron 64 artefactos cerámicos, de los cuales 52 son fragmentos de cuerpos y bases de vasijas globulares, dos son bordes engrosados o reforzados, dos son bordes simples, un tiesto con orificio horadado, un fragmento de tubo de pipa, cuatro tiestos con decoración lineal incisa y dos asas.

A continuación, se excavó un total de 27 cuadrículas de 1 x 1 $\mathrm{m}$, obteniendo dos dataciones que van desde $730 \pm 80$ años A.P. (LP-1559, carbón vegetal) y los $750 \pm 60$ años A.P., (LP-1569, carbón vegetal). La muestra está compuesta por 635 artefactos (Tabla 1), entre ellos 522 son fragmentos de lisos de cuerpo y bases globulares $(82,2 \%), 39(6,14 \%)$ son bordes sin decoración y $22(3,64 \%)$ presentan decoraciones incisas; 34 (5,35\%) segmentos de inflexión e intersección cuerpo-cuello presentan decoración incisa, geométrica lineal y en menor medida puntiforme. Se recuperaron además nueve fragmentos de asas $(1,10 \%)$, cuatro $(0,62 \%)$ fragmentos horadados o "torteros", cinco $(0,78 \%)$ artefactos caracterizados como otros y dos fragmentos de instrumentos indeterminados modelados en arcilla $(0,30 \%)$.

\section{Análisis arqueométricos}

En adelante resumiré los distintos estudios realizaron a lo largo de la última década desde este enfoque que eh postulado como multiproxi. Desde un principio el análisis cerámico contempló estudios arqueométricos que dividimos en A- estudios de procedencia, B- estudios estructurales y $\mathrm{C}$ - estudios funcionales.

\section{Estudios de procedencia}

En el primer caso (A), los estudios sobre procedencia realizados se centraron hasta el momento en el análisis de las pastas mediante TXRF (Total Reflection X-Ray Fluorescence Analysis), identificando, cuantificando 16 elementos (K, Ca, Ti, V, Cr, Mn, Fe, Ni, Cu, Zn, As, Rb, Sr, Zr, Y, Pb) y comparando los 


\begin{tabular}{|c|c|c|c|c|}
\hline Localidad Arqueológica & Sitios & Faja altitudinal & Sector & Fragmentos \\
\hline \multirow[b]{2}{*}{ Localidad Arqueológica } & \multirow{4}{*}{ Lago Meliquina } & & Sector 1 & 1.435 \\
\hline & & Faja Media & Sector 2 & 327 \\
\hline \multirow{3}{*}{$\begin{array}{c}\text { Meliquina } \\
\text {-LAM- }\end{array}$} & & & Sector 1 & 635 \\
\hline & & Faja Superior & Superficie. & 64 \\
\hline & Cueva Parque Diana & \multicolumn{2}{|c|}{ Componentes Superior y Medio } & 67 \\
\hline
\end{tabular}

Tabla 1. Síntesis de materiales recuperados y procedencia.

\begin{tabular}{|c|c|c|c|c|c|c|c|}
\hline Elementos & Arcilla II & Cerámica $1 \mathrm{~S} /$ Limpiar & Cerámica $2 \mathrm{~S} /$ Limpiar & Cerámica 3 Limpia & Cerámica $3 \mathrm{~S} /$ Limpiar & Cerámica $4 \mathrm{~S}$ /Limpiar & Cerámica 4 Limpi \\
\hline $\mathrm{K}$ & $3.34 \pm 0.1$ & $5.96 \pm 0.51$ & $5.64 \pm 0.13$ & $6.22 \pm 1.1$ & $6.28 \pm 0.1$ & $7.56 \pm 0.1$ & $6.39 \pm 0.5$ \\
\hline$(\mathrm{mg} / \mathrm{g})$ & 2.1 & 8.5 & 2.4 & 17 & 2.0 & 1.9 & 8.1 \\
\hline $\mathrm{Ca}$ & $17.9 \pm 0.1$ & $5.30 \pm 0.31$ & $6.65 \pm 0.66$ & $11.8 \pm 0.4$ & $11.1 \pm 0.5$ & $21.4 \pm 0.2$ & $17.6 \pm 8.8$ \\
\hline (mg/g) & 0.6 & 5.9 & 9.9 & 3.3 & 4.8 & 1.0 & 4.8 \\
\hline $\mathrm{Ti}$ & $5.38 \pm 0.4$ & $3.65 \pm 0.11$ & $4.77 \pm 0.32$ & $4.90 \pm 0.09$ & $4.49 \pm 0.2$ & $6.50 \pm 0.2$ & $4.81 \pm 0.11$ \\
\hline (mg/g) & 7.6 & 2.9 & 6.7 & 1.8 & 5.4 & 2.4 & 2.2 \\
\hline V & $192 \pm 0.7$ & $164 \pm 10$ & $140 \pm 4.2$ & $237 \pm 38$ & $188 \pm 8.5$ & $201 \pm 8.5$ & $187 \pm 1.4$ \\
\hline (mg/g) & 0.4 & 6.0 & 3.0 & 16 & 4.5 & 4.2 & 1.0 \\
\hline $\mathrm{Cr}$ & N.D & & $38.4 \pm 1.2$ & $52.3 \pm 3.4$ & $55.0 \pm 8.7$ & $61.1 \pm 8.6$ & $45.8 \pm 18$ \\
\hline (mg/g) & & & 3.1 & 6.4 & 16 & 14 & 38 \\
\hline $\mathrm{Mn}$ & $999 \pm 7.1$ & $409 \pm 13$ & $324 \pm 53$ & $708 \pm 74$ & $1176 \pm 385$ & $804 \pm 19$ & $825 \pm 46$ \\
\hline (mg/g) & 0.7 & 3.3 & 16 & 10 & 33 & 2.4 & 5.6 \\
\hline $\mathrm{Fe}$ & $49.4 \pm 1.5$ & $37.2 \pm 2.8$ & $44.6 \pm 0.4$ & $46.5 \pm 1.8$ & $44.5 \pm 1.5$ & $56.5 \pm 1.1$ & $45.3 \pm 2.9$ \\
\hline (mg/g) & 3.0 & 7.6 & 1.0 & 3.8 & 3.3 & 2.0 & 6.4 \\
\hline $\mathrm{Ni}$ & N.D & $30.2 \pm 5.0$ & N.D & N.D & N.D & N.D & N.D \\
\hline (mg/g) & & 17 & & & & & \\
\hline $\mathrm{Cu}$ & N.D & $44.3 \pm 0.8$ & $52.1 \pm 1.7$ & $34.6 \pm 0.7$ & $38.8 \pm 7.3$ & $63.3 \pm 4.0$ & $46.5 \pm 7.4$ \\
\hline (mg/g) & $(56.8 \pm 0.7)$ & 1.8 & 3.3 & 2.1 & 19 & 6.4 & 16 \\
\hline $\mathrm{Zn}$ & $96.5 \pm 28.4$ & $323 \pm 2.1$ & $148 \pm 0.7$ & $81.5 \pm 25$ & $73.2 \pm 7.2$ & $121 \pm 6.4$ & $68.0 \pm 1.1$ \\
\hline (mg/g) & 29 & 0.7 & 0.5 & 30 & 10 & 5.3 & 1.7 \\
\hline As & $65.5 \pm 25.8$ & N.D. & N.D. & & $45.8 \pm 14$ & N.D. & N.D. \\
\hline (mg/g) & 39 & & & & 29 & & \\
\hline $\mathrm{Rb}$ & N.D & $47.0 \pm 16$ & $37.7 \pm 4.5$ & $36.0 \pm 8.0$ & $57.4 \pm 16$ & $52.6 \pm 6.6$ & $43.5 \pm 13.6$ \\
\hline (mg/g) & $(38.5 \pm 1.2)$ & 34 & 12 & 22 & 28 & 13 & 31 \\
\hline $\mathrm{Sr}$ & $212 \pm 19.4$ & $132 \pm 20$ & $134 \pm 18$ & $210 \pm 4.2$ & $201 \pm 34$ & $347 \pm 2.1$ & $302 \pm 20$ \\
\hline (mg/g) & 9.2 & 15 & 14 & 2.0 & 17 & 0.6 & 6.6 \\
\hline $\mathrm{Zr}$ & $507 \pm 150$ & $166 \pm 2.8$ & $217 \pm 7.8$ & $484 \pm 133$ & $463 \pm 65$ & $407 \pm 44$ & $359 \pm 54$ \\
\hline (mg/g) & 30 & 1.7 & 3.6 & 28 & 14 & 11 & 15 \\
\hline Y & $47.0 \pm 7.5$ & $11.0 \pm 0.8$ & N.D & $25.8 \pm 2.6$ & N.D & $24.4 \pm 1.7$ & \\
\hline$(\mathrm{mg} / \mathrm{g})$ & 16 & 7.7 & & 10 & & 7.0 & \\
\hline $\mathrm{Pb}$ & & $80.5 \pm 5.0$ & $49.0 \pm 6.2$ & $» 40$ & N.D & $69.4 \pm 15$ & $42.6 \pm 6.2$ \\
\hline (mg/g) & & 6.2 & 13 & & & 22 & 15 \\
\hline
\end{tabular}

Tabla 2. TXRF (CNEA, Centro Atómico Constituyentes) sobre muestras de arcilla y artefactos cerámicos de LAM.

valores de cuatro artefactos cerámicos, dos del sitio LM-FS, S1 y otra muestra de dos artefactos cerámicos de sitios emplazados en el lago Lácar, a metros de la actual frontera con la república de Chile. Finalmente se tomó una muestra de las arcillas que afloran en el talud del arroyo que se ubica a 20 metros del sitio (Arcilla II). Esta última filtrada, amasada, secada, y una vez convertidas en placas fueron cocidas a $600^{\circ} \mathrm{C}$ y transformadas en cerámica. Las siete muestras fueron analizadas conjuntamente y los resultados comparados mediantes análisis multivariados de elementos con el objetivo de establecer o caracterizar grupos de pastas en base a su composición química (Figura 2) y de ser factible observar en los resultados la posibilidad de discutir la producción local de alfarería (Pérez, 2017).

Como resultado se confirmó la presencia de al menos dos grupos químicos entre las muestras de alfarería del sitio Lago Meliquina, incluyendo la presencia de un grupo químico de características similares al de la fuente de arcilla natural (previamente amasada y cocida) con alto contenido de $\mathrm{Zr}$, Mn, y 


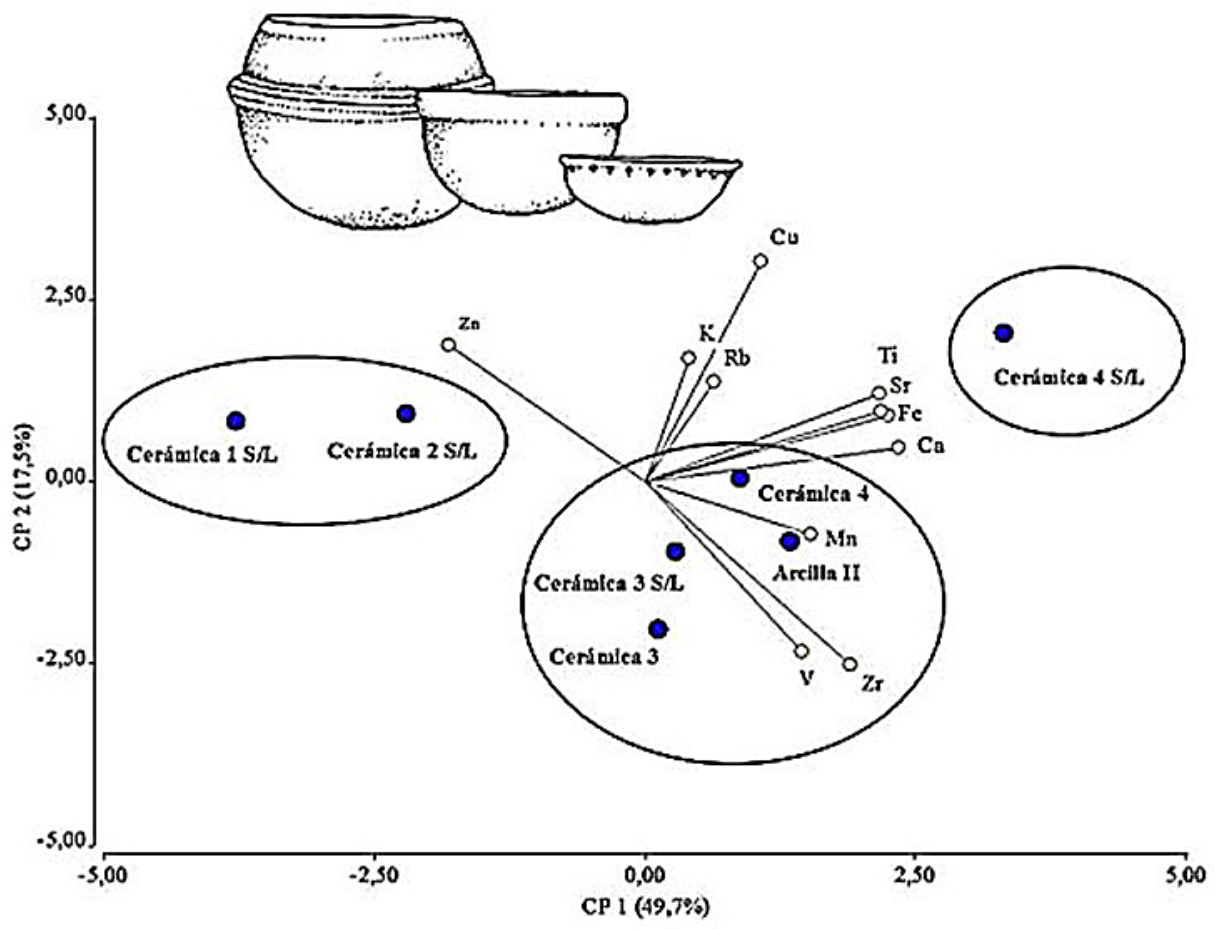

Figura 2. Grupos de arcillas de la LAM caracterizados por TXRF.

$\mathrm{V}$, recolectados en LM-FS, caracterizados como Cerámica 3 y 3 S/L, y otro como Cerámica 4, recuperado en el sitio Nonthué, a orillas del tramo Nonthué del lago Lácar, a $30 \mathrm{~km}$ de distancia en dirección noroeste, y a escasos 300 metros de la actual frontera chilena (Pérez, 2017). Otras dos muestras, consignadas como Cerámica $1 \mathrm{~S} / \mathrm{L}$ y Cerámica $2 \mathrm{~S} / \mathrm{L}$, pertenecen a un mismo grupo químico con alto contenido de Zn, casi ausente en las arcillas locales (Tabla 2, Figura 2). Es importante remarcar que la Cerámica 3 presenta engobe colorado, aunque cabe aclarar aquí que para evitar contaminación, en todos los casos los análisis químicos fueron realizados sobre muestras extraídas del interior (bajo el engobe). Podemos entonces verificar la manufactura local de vasijas monocromas pardas y con engobes colorados pulidos, a partir de pastas de origen local. Esto es un dato no menor, ya que generalmente se caracteriza la decoración rojo pintada como atributo de manufactura trasandina (Aldazabal et. al., 2015).

\section{Estudios estructurales}

Respecto a los estudios estructurales (B), me centraré aquí solamente en aquellos que realizamos utilizando imágenes de rayos $\mathrm{X}$ que permitieron ver la técnica de manufactura, distinguiendo modelado de rollo o rodete (Rye, 1981; Carr, 1993). El análisis radiográfico fue desarrollado previamente en muestras de Patagonia por Schuster y colaboradores (Schuster, 2010, 2014), estableciendo tamaño, proporción y distribución de inclusiones, como así también técnicas de manufactura partir a de la distribución de inclusiones y la presencia de áreas intersticiales recurrentes conformadas por la superposición de elementos como rollos de arcilla (Rye, 1981; Braun, 1982; Carr, 1993). Fragmentos correspondientes a dos vasijas fueron analizadas mediante RX en el laboratorio de diagnóstico por imágenes de la Facultad de Medicina de la Universidad Maimónides (CABA). Una de las muestras incluye partes de borde, cuerpo y base de la misma vasija (Figura 3). Pudimos apreciar la manufactura de tipo espiral a partir de rollos de $1 \mathrm{~cm}$ de diámetro desde la base de una vasija tipo olla de cuerpo globular sin base formatizada, es decir sin puntos de inflexión o intersección (Balfet, Fauvet Berthelot \& Monzón, 1992) evidentes entre cuerpo y base, lo cual es interesante para profundizar en los modos de hacer y aspectos identitarios (Gosselain, 2000), ya que, este tipo de vasija generalmente inicia su base por modelado y se continua luego las paredes mediante enrollado (Orton, Tyers \& Vince, 1997; Balfet et al., 1992).

\section{Análisis funcionales}

Respecto a los estudios funcionales (C), incluyeron el análisis de muestras procedentes de LM-FS y LM-FM. El trabajo se centró específicamente en obtener muestras de estructuras residuales y no así en huellas de uso. Respecto a la estructura residual, se realizaron análisis especializados para determinar fitolítos y ácidos grasos con la finalidad de obtener información más detallada sobre el uso/función de los recipientes cerámicos (Rice, 1999; Eerkens, 2005; Piperno, 2006). Pero podemos diferenciar entre las etapas de trabajo los estudios que se basaron en A- las sustancias adheridas a las superficies internas y externas de las paredes, B- sustancias que fueron absorbidas a través de microporosidades y grietas en las paredes de los recipientes y extraídas de los núcleos de los fragmentos y C- las improntas negativas de elementos (agregados intencionalmente o no) que pueden ser identificados. 

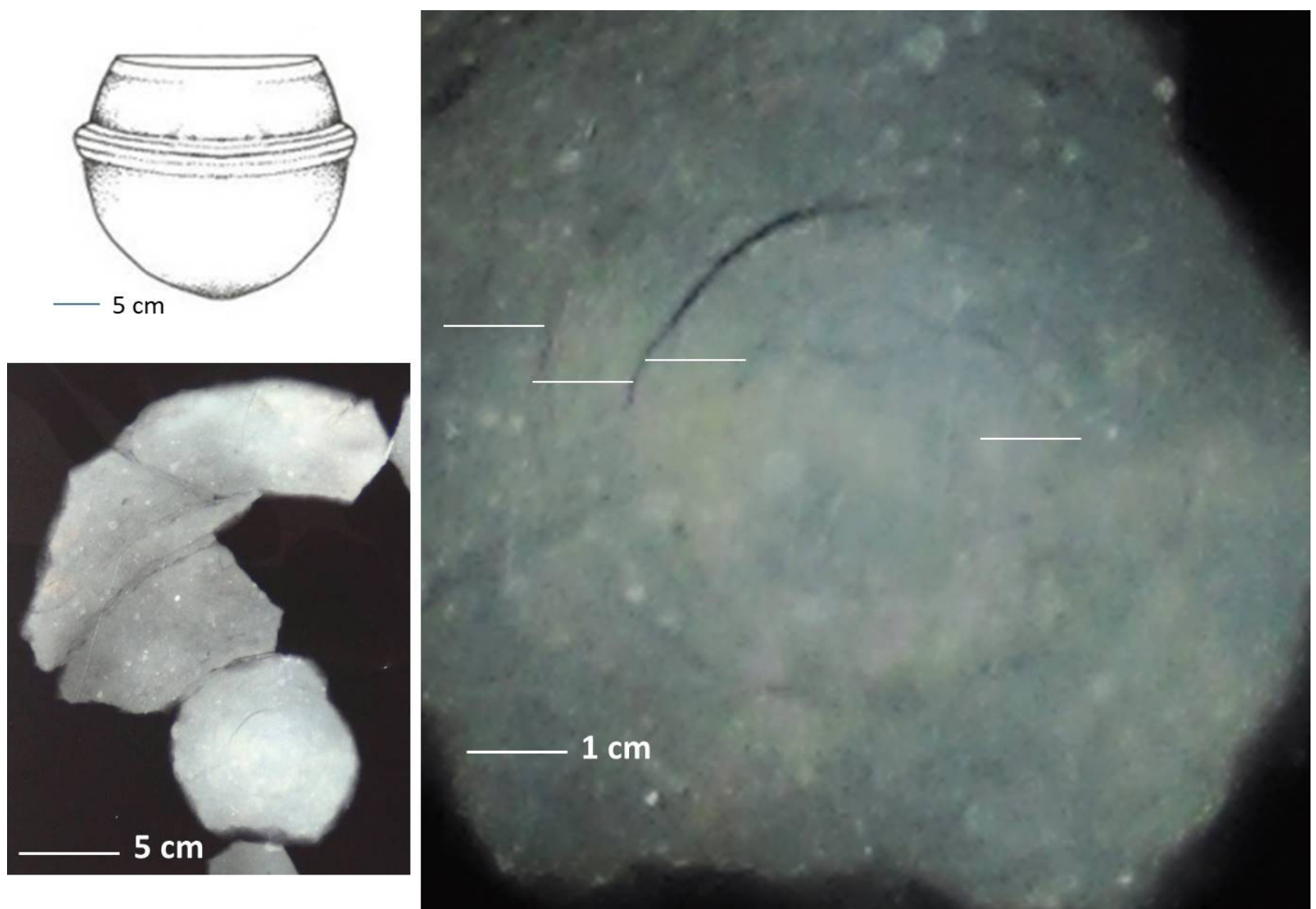

Figura 3. Detalle de RX de la base procedente de LM-FM.

\section{Sustancias adheridas}

\section{Estructuras silico-fitolíticas}

Se analizaron 11 tiestos cerámicos correspondientes a bases, diversos sectores de cuerpo y cuellos de vasijas globulares recuperados en estratigrafía de LM-FM entre las plantas 3 y 6; todos aportaron importantes comunidades fitolíticas correspondientes a gramíneas (Pérez \& Erra, 2011). La extracción e identificación fue realizada por la Dra. Georgina Erra en la Universidad de la Plata, donde se realizó una limpieza suave con franelas sobre cada una de las piezas, para remover el polvillo que pudieran contener o sedimento adherido y de este modo evitar contaminaciones. Una vez limpio, se procedió al raspado de las vasijas. Con el sedimento obtenido se realizó el montaje sobre portaobjetos para su observación al microscopio óptico. Se realizaron preparados temporarios con cada muestra en aceite de inmersión para facilitar el movimiento de los fitolitos y su observación 3D. El equipo empleado fue microscopio Hokken WPH 100 con aumentos de 40x de objetivos y de 16x de oculares. Para la caracterización morfológica de los silicofitolitos se utilizó la clave de Bertoldi de Pomar (1971).

Las observaciones evidenciaron la presencia de varios morfotipos de fitolitos (Pérez \& Erra, 2011), entre los que se destacan Estrobilolitas (rondel); Prismatolitas (Parallepipedal/ elongate), Flabeolitas (Cuneiform/parallepipedal bulliform cell, "fanshaped"), Acueolitas (hooks, prickles y macrohairs, "Point shaped") sin mayor poder diagnóstico a nivel taxonómico que la clasificación general de "gramíneas", pero habiéndose encontrado además, entre el grupo de los Estrobilolitas, abundantes muestras correspondientes a Wavy/Ruffle toprondel (Figura 4A), correspondiente a las partes comestibles de maíz. Entonces, por un lado, sabemos que las asignaciones taxonómicos mediante estudios de residuos sílico-fitolíticos es muy parcial a causa de la falta de material comparativo para el registro botánico regional, pero por otro lado, sabemos que los fitolitos presentes corresponden en casi su totalidad a gramíneas, lo que permite descartar la presencia de residuos provenientes de plantas arbóreas por ejemplo, y si contar con acceso a recursos provenientes de plantas cultivadas entre $920 \pm 60$ años A.P. (Pérez \& Erra 2011). Por debajo de esta datación, en Planta o Capa 6 encontramos las mismas asociaciones silico-fitolíticas, junto a Halteriolitas (bilobate short cell, "dumb-bell"), que corresponderían a otros partes de la planta de maíz, como tallo y hoja. Estas ocupaciones inferiores registradas en LM-FM presentan la mayor variedad del repertorio de alfarería Pitrén, especialmente pintada negro sobre engobe colorado y modelada (Pérez, 2010b; Pérez \& Erra, 2011).

Se observó que la mayor variedad de fitolitos se encuentra representada en los niveles alfareros más tempranos, identificados hasta ahora como "Componente Medio" de LAM, donde la diversidad de estilos alfareros es la más importante (Figura 5), y dentro de las vasijas se encuentran residuos de todas las partes de la planta de maíz, incluyendo las partes comestibles y no comestibles (Figura 4B). Mientras que en los 


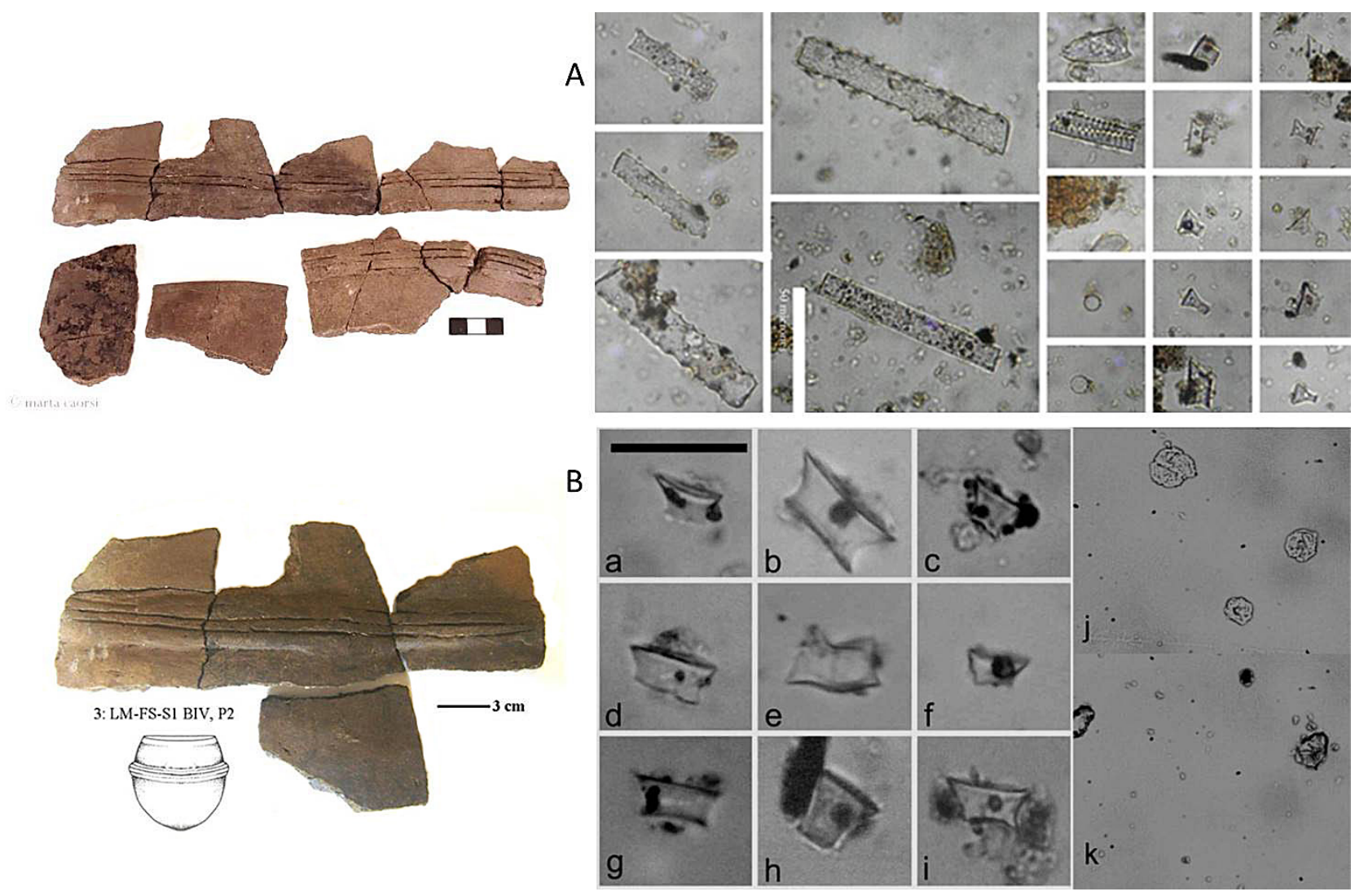

Figura 4. A-Sector superior, muestra cerámica y fitolítos identificados (escala $50 \mu \mathrm{m}$ ). B-Sector inferior, a-i fitolítos Wavy/Ruffle top-rondel (escala $20 \mu \mathrm{m}$ ), correspondiente a las partes comestibles de maíz y j-k almidones termoalterados de maíz procedentes del mismo recipiente contenedor.
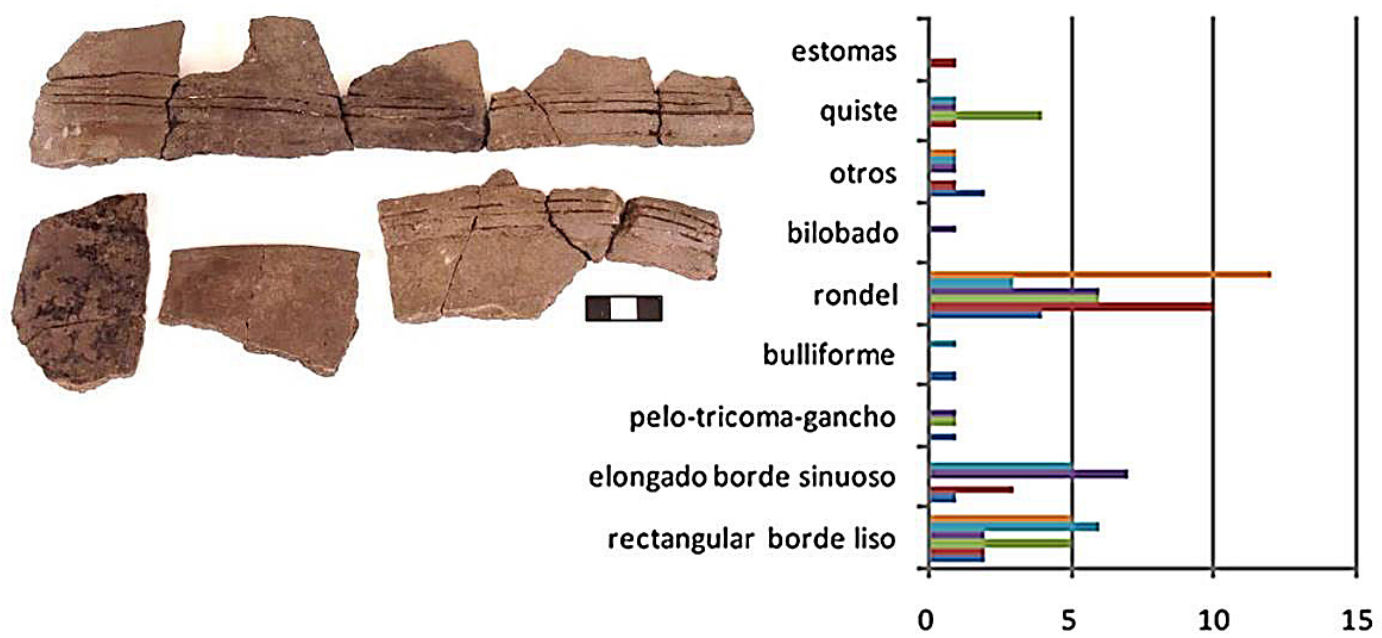

LMFM S2 B1P4

口LMFS S2 sondeo

口LMFM S2 B1P6

口LMFM S2 B1PS

口LMFM S2 B1 P3

elongado borde sinuoso

rectangular borde liso

0

15

Figura 5. Fitolitos, estomas, quistes y otros identificados en LM-FS y LM-FM, S2.

contextos alfareros superiores, que hemos caracterizado como “Componente Superior" de LAM, la alfarería monocroma, buena parte de manufactura local, es mayoritaria, y donde los residuos sílico-fitolíticos presentan menos variabilidad, destacándose la presencia de residuos de maíz característicos de las partes comestibles de la planta (Pérez \& Erra, 2011).
Ácidos grasos

La determinación de ácidos grasos se realizó a partir de la cromatografía gaseosa sobre 16 fragmentos cerámicos procedentes de LM-FM, Sector 1 (muestras 1 a 10) y Sector 2 (muestras 11 a 16). Este proceso técnico y la detección de los distintos compuestos fue realizado por los Dres/as. Carlos 
Luquet, Mariela Nicolini y Pablo Ugalde en el laboratorio del CEAN y del INIBIOMA (CONICET- UNC-UNCO) en Junín de los Andes, Neuquén con un cromatógrafo Shimadzu GC-9A; columna capilar Omega wax 320 de $30 \mathrm{~m}$ con $0,32 \mathrm{~mm}$ ID.

La extracción de lípidos se practicó sobre el material obtenido del raspado de la pieza y de acuerdo al método de Folch, Lee \& Stanley (1957), con cloroformo-metanol (inicialmente 1:1 y 2:1 en la segunda extracción, v/v). Los lípidos obtenidos fueron esterificados con Borotrifluoruro-metanol, siguiendo la técnica de Morrison \& Smith (1964).

La composición de los éster metílicos de los ácidos grasos se analizó en un cromatógrafo Shimadzu GC-17A usando una columna capilar Omega wax 320 de $30 \mathrm{~m}$ con $0,32 \mathrm{~mm}$ de diámetro y 0,25 um de film. Las condiciones de trabajo fueron: Temperatura de inyección $250^{\circ} \mathrm{C}$, temperatura del detector $260^{\circ} \mathrm{C}$, temperatura inicial del horno/columna $90^{\circ} \mathrm{C}$ incrementado $4^{\circ} \mathrm{C} / \mathrm{min}$ hasta los $230^{\circ} \mathrm{C}$ y luego $2^{\circ} \mathrm{C} / \mathrm{min}$ hasta a $240^{\circ} \mathrm{C}$ allí se mantuvo durante 23 minutos, luego incremento de $5^{\circ} \mathrm{C} / \mathrm{min}$ hasta temperatura final $260^{\circ} \mathrm{C}$ durante cinco minutos más. Tiempo total 75 min. Como gas de transporte se utilizó Nitrógeno. La relación del "split" fue 1:50. Los ésteres metílicos de los ácidos grasos se identificaron comparando las muestras con un estándar auténtico Supelco 37Comp.FAME Mix (Lot: LB66298) y en base a sus tiempos de retención relativos. Los resultados se expresan como porcentaje relativo de ácidos grasos.

Se pudo identificar al menos 18 ácidos grasos, entre éstos, los necesarios para aplicar índices y modelos de Eerkens (2005), con calibración de Melanay, Przybylski \& Sherriff (1999). Los resultados sugieren el uso de recursos vegetales que incluyen semillas, frutos, raíces, y en menor proporción mamíferos terrestres (Figura 6).

\section{Sustancias absorbidas}

\section{Cultivo y análisis molecular de levaduras}

Una muestra de fragmentos cerámicos fue analizada por el Dr. Christian López y colaboradores en el laboratorio de Biodiversidad y Biotecnología de Levaduras en dependencias del Departamento de Química, Facultad de Ingeniería del
PROBIEN, CONICET-UNCo, Neuquén. En la actualidad hay más de 35 muestras bajo análisis de diversos sectores de los lagos Meliquina, Lácar y Lolog, pero los primeros resultados provienen del análisis de los conjuntos cerámicos de LM-FM, $\mathrm{S} 1$, los cuales han arrojado resultados positivos (Pérez et al., 2016), pudiendo extraer material orgánico de las paredes internas de los fragmentos luego de minuciosos procesos destinados a evitar contaminación de la muestra según los protocolos de biotecnología más adecuados.

El análisis de la secuencia de las colonias de levadura recuperadas evidenció la presencia de 11 especies de levadura diferentes (Figura 7). Curiosamente, solo se detectaron cuatro especies diferentes cuando las muestras se incubaron a temperaturas bajas $\left(13^{\circ} \mathrm{C}\right)$ y altas $\left(25^{\circ} \mathrm{C}\right)$, mientras que las 11 especies de levadura se recuperaron cuando las muestras se incubaron a temperatura intermedia $\left(20^{\circ} \mathrm{C}\right)$. El noventa por ciento de las cepas identificadas correspondían a levaduras basidiomicetosas y pertenecían a los géneros Aureobasidium, Filobasidium, Holltermaniella, Naganishia, Solicoccozyma y Vishniacozyma (Pérez et al., 2016).

A continuación se procedió a la secuenciación genética de las muestras, confirmando la presencia de Saccharomyces eubayanus, una levadura adaptada a climas templados que puede producir fermentación a bajas temperaturas. Se encuentra en forma natural en bosques de Nothofagus sp. y Araucaria sp. (Rodríguez, Pérez-Través, Sangorrín, Barrio \& Lópes, 2014; Pérez, Vera Macaya, Rodríguez, Lópes \& Lanata, 2020).

Entre los resultados obtenidos se identificó la levadura fermentativa criotolerante Sacharomyses eubayanus absorbida dentro de las paredes de recipientes cerámicos datados entre 920 a 750 años A.P. En las mismas vasijas se identificaron residuos sílico-fitolíticos y almidones termoalterados de Zea mays (Figura 4B), además de ácidos grasos de semillas y frutos (Figura 5) potencialmente fermentativos. A partir de estas múltiples evidencias se postula la presencia de la levadura Saccharomyces eubayanus como derivado de la elaboración, almacenamiento, transporte, consumo y/o servicio de bebidas fermentadas entre recipientes cerámicos del sitio (Pérez et al., 2020).
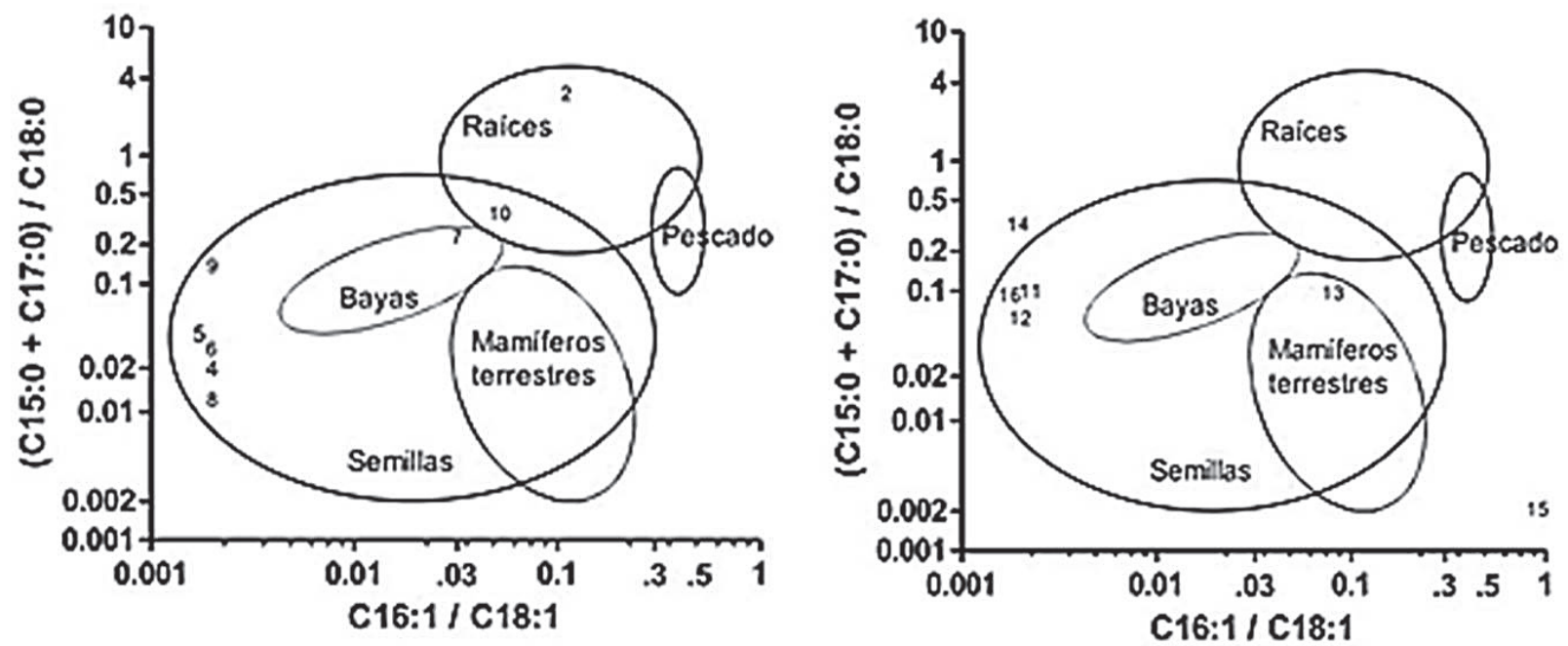

Figura 6. Resultados de ácidos grasos recuperados en fragmentos cerámicos de LM-FM, Sectores 1 y 2 (izquierda y derecha respectivamente). 


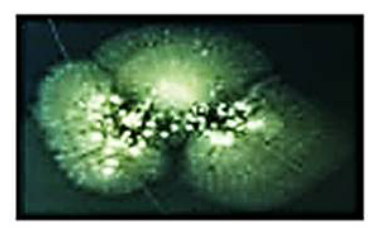

A. pullulans

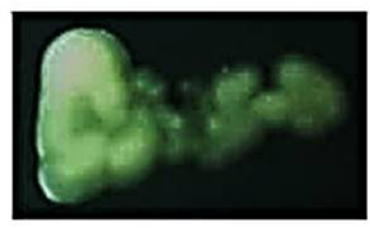

N. cantarctica

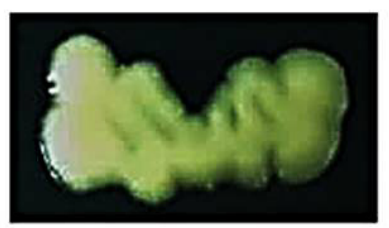

N. diffiuens

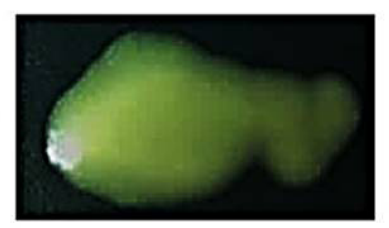

F. oeirensis

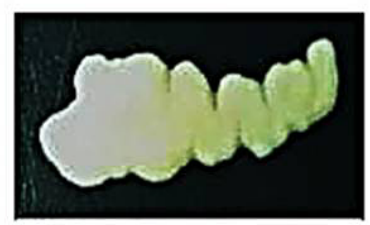

N. bhutconensis

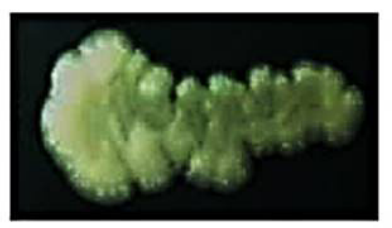

S. eubajanus

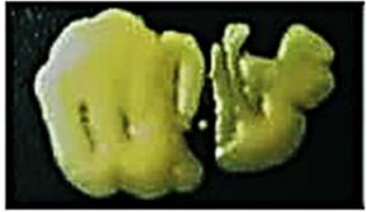

H. wattica

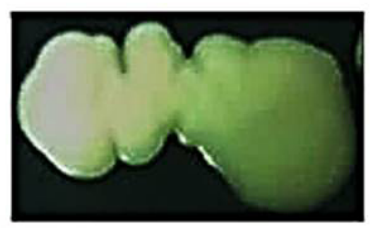

N. cereails

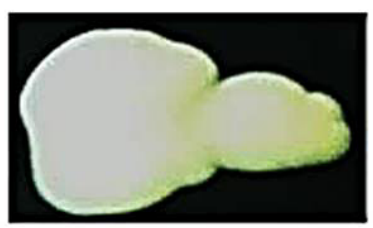

S. aerius

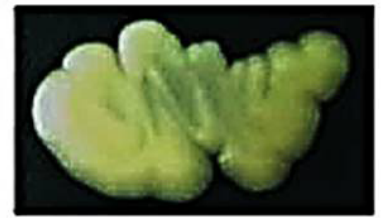

S. phenolicus

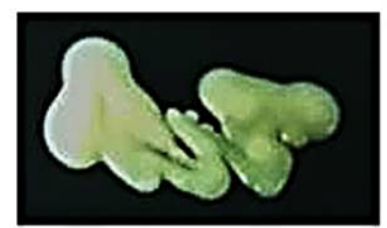

V. tephrensis

Figura 7. Cultivos de levaduras de alfarería de LM-FM

\section{Improntas de sustancias y/o elementos}

La muestra proviene de un fragmento cerámico procedente de la planta 4 del sitio Cueva Parque Diana datada en $760 \pm 60$ años ${ }^{14}$ C A.P. (LP1697, carbón vegetal).

La caracterización de las improntas requirió el empleó de un microscopio digital DinoLite AM 413ZT PRO entre 28 y 200 x de aumentos con luz polarizada. Algunos atributos secundarios de la traza fueron analizados a partir de imágenes tomadas por la Unidad de Microscopía Electrónica de Barrido (MEB), Facultad de Ciencias Naturales y Museo, Universidad Nacional de La Plata (Figura 8B). Posteriormente, los atributos registrados en las improntas fueron comparados con material vegetal de herbario, en esta etapa se consultó la colección digital del Instituto de Botánica Darwinion, IBODA-CONICET (Pérez et al., 2014, 79).

Se trata de atributos bio y morfométricos específicos derivados de la aplicación intencional de dos cariópsis, una completa y otra incompleta, identificando claramente la cuarta parte de su segmento distal (Figura 8A). Lo que significa que ambas están dispuestas de forma longitudinalmente paralelas, con el antecio proyectado hacia arriba, distanciadas $1,1 \mathrm{~cm}$ una de otra. Sus medidas son 4,61 mm de largo y 1,21 mm de ancho, sin contar la parte incompleta que se observa del antecio. Presenta evidentes atributos negativos del antecio, gluma (Figura 8C) y arista de una cariópsis. Atributos y morfología que permiten caracterizarla como Poacea. En la gluma se observan con bajos aumentos $(22 \mathrm{x}$ y 39 x) venas longitudinales en toda la superficie. La morfología de la impronta refleja que la cariópsis se encontraba encerrada dentro de la lema al momento de ser impresa a la vasija en textura blanda o cuero. La misma fue aplicada dactilarmente, y la ubicación y recurrencia en la repetición del motivo permiten plantear que se trata de un aspecto decorativo (Pérez et al., 2014, 80).

\section{A modo de sintesis}

En la LAM se recuperó una importante muestra de artefactos cerámicos, tanto en sitios bajo reparo rocoso como a cielo abierto. Pudimos obtener muestras con excelente integridad en el bosque para realizar distintos análisis que incluyeron materiales tanto orgánicos como inorgánicos. Sobre la misma realizamos una serie de análisis que hemos organizado en: estudios de procedencia, estructurales y funcionales. Los últimos incluyeron muestras orgánicas e inorgánicas pero todos procedentes del procesamiento y la contención de sustancias alimenticias, hidratantes y estimulantes de origen vegetal y animal. Estos estudios fueron subdivididos en sustancias adheridas, sustancias absorbidas e improntas negativas.

En cuanto a procedencia, los resultados de la comparación cuali y cuantitativa de elementos analizados mediante TXRF sugiere la presencia de dos grupos químicos entre los artefactos analizados de LM-FS. Uno de posible producción local por su similitud con las muestras reproducidas a partir de arcillas en inmediata vecindad (Arcillas II), y otra que consideramos no local, similar a muestras procedentes de sitios la cuenca Lácar/ Nonthué, cercanos a la frontera chilena, y naciente de la cuenca y área arqueológica binacional del río Valdivia, con mayor representación en el sector occidental cordillerano (Pérez 2016).

Respecto a los estudios estructurales, mediante análisis de imágenes radiográficas pude observar que las bases más 


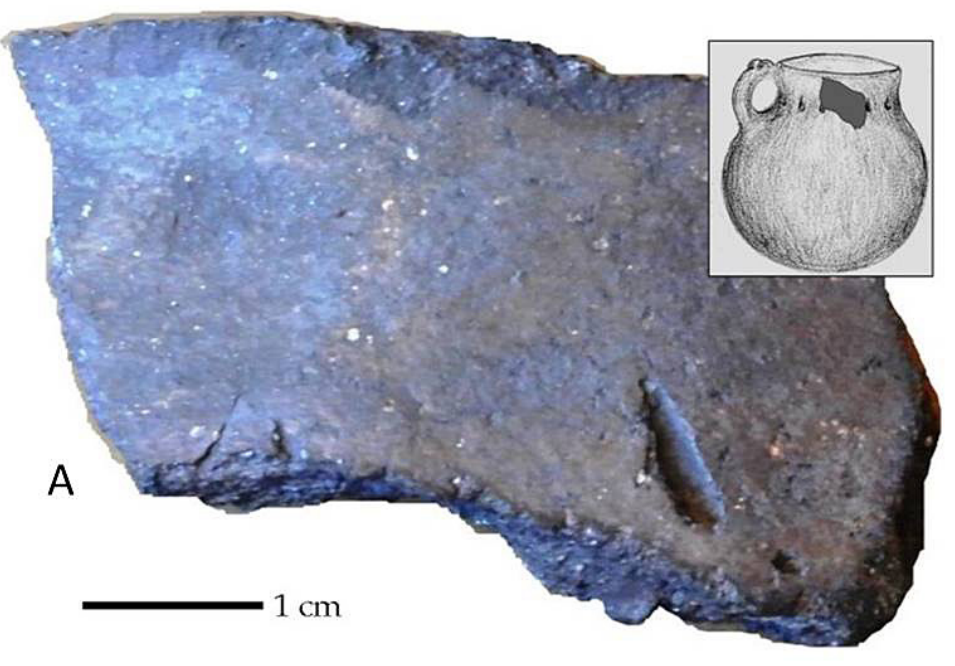

B

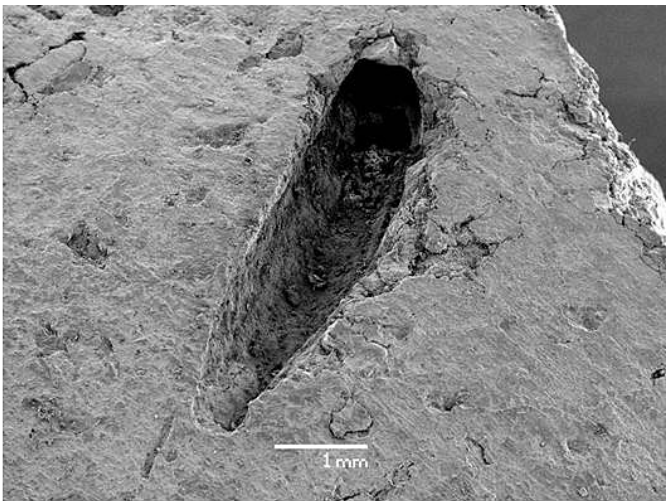

C

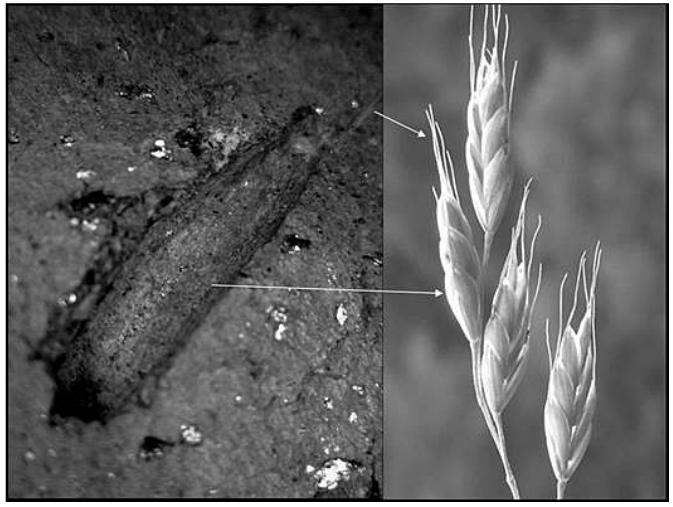

Figura 8. A- fragmento con impronta y ubicación sugerida, B- detalle de contorno de la impronta en MBE,

C- detalle de atributos de gramínea Bromus $s p$.

completas encontradas en LM-FM y LM-FS pertenecían a recipientes globulares manufacturados por medio de técnicas de superposición de rollos o rodetes en espiral, en lugar de partir de modelado.

Los estudios funcionales sugieren la contención y/o procesamiento de distintos recursos, pero predominando los de origen vegetal. Estos estudios fueron organizados entre aquellos basado en el análisis de sustancias adheridas a las caras de las paredes de los fragmentos cerámicos, los absorbidos por microporosidades o fracturas y las improntas negativas.

Las sustancias adheridas permitieron realizar análisis de estructuras sílico-fitolíticas, almidones y ácidos grasos. Entre los primeros se identificó la presencia mayoritaria de gramíneas Poaceas, aunque a nivel más específico pudimos identificar el registro más austral del continente de Zea mays. Los fitolítos de todas las partes de la planta encontrados en los niveles cerámicos más antiguos de LM-FM, S2 o Componente Medio de la LAM sugieren que son residuos acumulados de uso de los recipientes en áreas de producción de maíz, específicamente en distintos sectores de costa y valles centrales del área centro sur de Chile (Pérez \& Erra, 2011), asociados a cerámica negativa negra sobre engobe colorado y asas puente (Pérez, 2010). En los niveles cerámicos del Componente Superior, los residíos identificados de fitolítos y almidones corresponden en mayor medida a las partes comestibles de la planta como el marlo y la semilla, lo que nos permitió postular que a la LAM el maíz puede provenir de otras áreas pero es procesada y contenida en recipientes de manufactura local. En suma, en el Componente medio las personas que arriban temporalmente a la LAM desde áreas que incluyen producción de cultigenos como el maíz, transportan recipientes cerámicos que pudieron contener este recurso, mientras que en los Niveles Superiores, el maíz está circulando mayores distancias que las personas y los recipientes cerámicos contenedores (Pérez et al., 2020).

A continuación, pudimos identificar al menos 18 ácidos grasos, entre éstos, los necesarios para aplicar índices y modelos de Eerkens (2005), con calibración de Melanay et al. (1999), discriminando recursos vegetales como bayas y semillas como predominantes en las muestras. Estos resultados son concordantes además con los fitolítos y almidones, especialmente porque entre los recipientes contenedores del Componente Superior de la LAM habíamos identificado fitolítos de semillas o granos de maíz, además de almidones de los mismos cuya morfología denota la alteración térmica, la cual puede ser producto de la cocción para alimentación, pero también como parte de procesos de producción de bebidas fermentadas (Pérez et al., 2020).

Entre los residuos absorbidos y recuperados de los núcleos de los fragmentos se detectó la presencia, aislaron y cultivaron 11 especies diferentes levaduras (Pérez et al., 2016). El análisis molecular confirmó la presencia prehispánica en muestras de la LAM datadas entre 920 y 730 años A.P. de la especie criotolerante Saccharomises eubayanus, levadura implicada en la fermentación alimentos y bebidas (Pérez et al., 2020).

Finalmente, un fragmento cerámico procedente de CPD presenta atributos superficiales que, por medio de análisis bio morfológicos (partes componentes, morfología, tamaño, entre otros) por medio de Microscopia de Barrido Electrónico, se pudo identificar la incorporación intencional (posiblemente decorativa) de la impronta de dos cariópsis de la especie Bromus sp. También conocida como cebada araucana, una de las 3 gramíneas de este 
género (madi, mango y teka) recurrentemente mencionadas por los conquistadores españoles como parte de los cultigenos nativos (Pérez, Reyes Álvarez \& Erra, 2013).

\section{Conclusiones}

En sitios boscosos norpatagónicos la alfarería es abundante y presenta buena integridad y resolución para realizar estudios de procedencia, estructurales y funcionales desde un abordaje arqueométrico. Gracias a ello, las interpretaciones que hemos realizado hasta el momento acerca de algunos aspectos funcionales, de procedencia y estructurales, se han basado en la descripción de resultados de distintos análisis fisicoquímicos, radiométricos, biotecnológicos, moleculares y de diagnóstico de imágenes, en lugar de limitarse al uso de atributos morfológicofuncionales y tipológicos, los cuales sin duda enriquecerán el trabajo y las interpretaciones realizadas una vez que se cuente con mayor número y más precisas reconstrucciones de los recipientes contenedores de la LAM.

Entre los estudios de procedencia se identificó la producción local de recipientes a partir de arcillas disponibles en inmediata vecindad, junto a otro grupo químico de arcillas de disponibilidad no local, similar a muestras de las cuencas Lácar/Nonthué, del sector oriental de la cuenca Valdiviana. Respecto a los estudios estructurales, me centré aquí en información que nos habla de los modos de hacer, como la manufactura de bases cóncavas de vasijas globulares a partir de superposición y elevación en espiral de rollos de $1 \mathrm{~cm}$ de espesor en lugar de partir de modelado.

En cuanto a los estudios funcionales, en la LAM los estudios arqueométricos han permitido identificar la presencia de una estrategia económica predominantemente recolectora, (hojas, bayas y semillas), complementada con recursos que sugieren cierto manejo como el Bromus sp. y otras especies no locales domesticadas como el maíz. La identificación de levaduras fermentativas criotolerantes y la alteración de los almidones sugieren que el maíz, al igual que otras semillas y frutos, puedan ser materia prima de bebidas fermentadas. En suma, los estudios arqueométricos aplicados desde enfoques y técnicas múltiples amplían el repertorio de especies identificadas para la Patagonia continental argentina y sugieren una estrategia económica mixta para momentos alfareros tardíos, es decir durante el último milenio y previo al contacto hispano-indígena, y cada vez más vinculado al desarrollo histórico de las poblaciones que tradicionalmente se han circunscrito en la literatura arqueológica a la vertiente occidental cordillerana, como parte de un mismo territorio.

\section{Agradecimientos}

Este trabajo es parte de un Programa de Investigación de la Dirección de Investigación, Vicerrectoría de Investigación y Postgrado, Universidad Católica de Temuco, Proyecto 2020PRO-AP-01, Alberto E. Pérez (IR), "Grupo de Arqueometría de la Universidad Católica de Temuco. Estudios funcionales físico-químicos y biotecnológicos sobre alfarería temprana del centro sur de Chile". Además, buena parte de estos trabajos contaron con financiamiento de los proyectos y subsidios PICT 2011-1738 (ANPCyT), PI04-173 (UNCo) y PICT V 2014-1558 (ANPCyT). Agradecemos el apoyo de la Administración de Parques Nacionales (APN No 834).

\section{Bibliografía}

Adán, L., Mera, R., Navarro, X., Campbell, R., Quiróz, D. \& Sánchez, M. (2016). Historia prehispánica en la región centro sur de Chile: Cazadores-recolectores holocénicos y comunidades alfareras (ca. 10.000 años a.C. hasta 1.550 d.C.). En: Prehistoria en Chile. Desde sus primeros habitantes hasta los Incas. F. Falabella, M. Uribe, L. Sanhueza, C. Aldunate y J. Hidalgo editores, pp. 401-442. Santiago. Sociedad Chilena de Arqueología.

Aldazabal, V., Reinoso, M., Freire, E., Halac, E., Polla, G. \& Custo, G. (2015). Aportes de la arqueometría al conocimiento de la pintura en la cerámica de cazadores recolectores del área lago Traful. En O. Palacios, C. Vázquez \& N. Ciarlo (Eds), Patrimonio cultural: la gestión, el arte, la arqueología y las ciencias exactas aplicadas (pp. 243-251). Buenos Aires. CONEA-CONICET, Editorial Nuevos tiempos.

Barnett, W. \& Hoopes, J. W. Eds, (1995). The emergence of pottery. Technology and innovation in ancient societies. Smithonian Institution. Washington and London.

Balfet, H., Fauvet Berthelot, F., \& Monzón, S. (1992). Normas para la descripción de vasijas cerámicas. México. Centre d'Études Mexicaines et Centraméricaines, (CEMCA).

Bertoldi de Pomar, H. (1971). Ensayo de clasificación morfológica de los silicofitolitos. Ameghiniana, 8 (34), 317-328.

Braun, D. P. (1982). Radiographic analysis of temper in ceramic vessels: goals and initial methods. Journal of Field Archaeology, 9 (2), 183-192.

Carr, C. (1993). Identifying individual vessels with radiography. American Antiquity, 58 (1), 96-117.

Di Prado, V. (2017). Propuesta para el análisis a nivel macroscópico de cerámicas arqueológicas: un abordaje desde el centro-este de Argentina. Comechingonia. Revista de Arqueología, 21 (1), 261-286.

Eerkens, J. W. (2005). GC-MS Analysis and fatty acid ratios of archaeological potsherds from the western Great Basin of North America. Archaeometry, 47 (1), 83-102.

García, C. (2010). Continuidad, cambio cultural y complejización entre cazadores-recolectores, reflexiones a partir de los datos arqueológicos de la región de Calafquén, Sur de Chile. Revista Werken, 12, 91-108.

Gosselain, O. P. (2000). Materializing Identities: An African Perspective. Journal of Archaeological Method and Theory, 7 (3), 187-217

Jordan, P., \& Zbelevil, M., Eds., (2009). Ceramic before farming. The dispersal of pottery among prehistoric Eurasian huntergatherers. Wanut Creek, CA: Left Coast Press.

Folch J, Lees M. \& G.H.S. Stanley, (1957). A simple method for the isolation and purification of total lipides from animal tissues. The Journal of Biological Chemistry, 226, 497-509.

Malainey, M. E., Przybylski, R. \& Sherriff, L. B. (1999). The Effects of Thermal and Oxidative Degradation on the Fatty Acid Composition of Food Plants and Animals of Western Canada: Implications for the Identification of Archaeological 
Vessel Residues. Journal of Archaeological Science, 26, 95103.

Morrison, W. R. \& Smith, L. M. (1964). Preparation of fatty acid methyl esters and dimethylacetals from lipids with Boron Fluoride-Methanol. Journal Lipid Research, 1964, 600-8.

Orton, C., Tyers, P. \& Vince, A. (1997). La cerámica en arqueología. Barcelona. Editorial Crítica.

Pérez, A. E. (2010). La Localidad Arqueológica "Lago Meliquina”, Dto. Lácar, Neuquen. El registro arqueológico del interior y borde de bosque en Norpatagonia. En: Actas y Memorias del XVII Congreso Nacional de Arqueología Chilena (2006), pp. 515-1528. Valdivia. Sociedad Chilena de Arqueología.

Pérez, A. E. (2011). Algunas reflexiones sobre la alfarería del Centro Sur de Chile y Ambientes Lacustres Precordilleranos de la Patagonia Septentrional Argentina. En P. Navarro Floria y W. Delrio (Comps), Cultura y Espacio. AraucaníaNorpatagonia (pp. 293-315). Río Negro. Universidad Nacional de Río Negro.

Pérez, A. E. (2016). El registro arqueológico de la cuenca binacional del río Valdivia. La integración de su fuente, el lago Lácar, sector oriental cordillerano. En M. A. Nicoletti, Nuñez, A. \& Nuñez, P. (Eds), Araucania-Norpatagonia. Discursos y representaciones de la materialidad, ( pp. 167194). Bariloche, Río Negro.

Pérez, A. E. (2017). La ocupación del bosque meridional neuquino durante la Anomalía Climática Medieval (800 1400 DC), (Tesis Doctoral), Departamento de Antropología, Facultad de Filosofía y Letras, Universidad de Buenos Aires. Buenos Aires.

Pérez, A. E. (2020). Alfarería arqueológica del Centro Sur de Chile y la Patagonia Noroccidental Argentina, hacia su integración regional. En Schuster V. \& Pérez, A. E. (Eds), Alfarería Arqueológica de la Patagonia, (pp. 115-138). Buenos Aires. Editorial Vázquez Mazzini.

Pérez A. E. \& Erra, G. (2011). Identificación de maíz en vasijas recuperadas de la Patagonia Noroccidental Argentina. Magallania, 39 (2), 309-316.

Pérez A. E., \& Reyes, V. (2009). Técnica improntas de hojas. Algunas reflexiones acerca de su novedoso registro en la vertiente occidental cordillerana. Magallania, 37(1), 113132.

Pérez, A. E., Reyes Álvarez, V. \& Erra, G. (2013). Economías mixtas de la Patagonia Noroccidental Argentina y centro sur de Chile. En Nicoletti M. A. \& Nuñez P. (Compiladores), Araucania-Norpatagonia: la territorialidad en debate. Perspectivas ambientales, culturales, sociales, políticas y económicas, (pp. 119-136). Río Negro. IIDyPCa,URNCONICET.

Pérez, A. E., Aguirre, M. G. \&. Graziano, J. E. (2015). Improntas de Cariópsis de gramíneas (Poaceae) en un fragmento de alfarería de Patagonia Noroccidental Argentina. Revista de Antropología del Museo de Entre Ríos, 1 (1), 79-87.

Pérez, A. E., Reyes Álvarez, V. \& Hermann, L. (2012). Alfarería con impronta de hojas por técnica de reserva en la Patagonia
Noroccidental Argentina. Revista Chungara, 44 (4), 593-603.

Pérez, A. E., Sugrañes, N. \& Otaño, I. (2015). Fracturas en Alfarería de la Patagonia Noroccidental Argentina. Mundo de Antes 9, 79-97.

Pérez, A. E., Schuster, V. \& Jofré, D. (2018). Amphibiomorphic Modeled and Painted Pottery from Argentine Patagonia and Central-Southern Chile. Functional Interpretation and Identification of Species Based on Mimetic and Aposematic Traits. Open Archaeology, 4 (1), 394-405.

Pérez, A. E., Vera Macaya, D., Rodríguez, M. E., Lópes, C. A, Lanata, J. L. \& Schuster, V. (2016). Determinación genética de levaduras procedentes de vasijas de cerámicas arqueológicas de la región de bosques y lagos andino norpatagónicos (cuencas Meliquina, Lácar y Lolog). Neuquén, Argentina. Actas del XIX CNAA, Serie Monográfica y Didáctica (pp. 1125-1132). Tucumán. Facultad de Ciencias Naturales e I. M. L., Universidad Nacional de Tucumán.

Pérez, A. E., Vera Macaya, D. Rodríguez, M. E., Lópes, C. A. \& Lanata, J. L. (2020). Primer registro prehispánico e implicancias de la presencia de una levadura fermentativa criotolerante Saccharomyces eubayanus en alfarería de la Patagonia Noroccidental Argentina. Manuscrito inédito.

Piperno, D. R. (2006). Phytoliths. A Comprehensive guide for Archaeologist and Paleoecologists. Lanham. Altamira Press.

Rice, P. M. (1999). On the origins of pottery. Journal of Archaeological Method and Theory, 6, 1-54.

Rye, O., (1981). Pottery Technology. Taraxacum, Washington D.C.

Rodríguez, M. E., Pérez-Través, L., Sangorrín, M. P., Barrio, E. \& Lópes, C. A. (2014). Saccharomyces eubayanus and Saccharomyces uvarum associated with the fermentation of Araucaria araucana seeds in Patagonia. FEMS Yeast Res., 14, 948-65.

Skibo J. \& Feinman, G. M. Eds, (1999). Pottery and People. A Dynamic Interaction. Foundations of Archaeological Inquiry. University of Utah.

Skibo, J., M. E. Malainey \& S. M. Kooiman (2016). Early pottery in the North American Upper Great Lakes: exploring traces of use. Antiquity, 90 (353), 1226-1237.

Schuster, V. (En prensa). Rayos X en la cerámica arqueológica de Patagonia: primeras experiencias para la costa y meseta central del Chubut. En. XVII Congreso Nacional de Arqueología Argentina. Mendoza.

Schuster, V. (2014). Diferentes técnicas para el mismo problema: el estudio tecnológico de un conjunto cerámico fragmentario (Costa Nordeste del Chubut, Patagonia Argentina). Comechingonia Virtual, 4(1), 1-26.

Schuster, V. (2020). Prólogo. En Schuster V. \& Pérez, A. E. (Eds), Alfarería Arqueológica de la Patagonia, (pp. 11-15). Buenos Aires. Editorial Vázquez Mazzini.

Watchman, A. L. (2001). Archaeometry. International Encyclopedia of the Social \& Behavioral Sciences; Editorsin-Chief: Neil J. Smelser and Paul B. Balte. 
Wells, C. E. (2018). Archaeological Chemistry: Definition. En C. Smith (Ed.), Encyclopedia of Global Archaeology. Springer International Publishing AG, part of Springer Nature. 
